\title{
A Survey on Fake News Detection Techniques and using a Blockchain based System to Combat Fake News
}

\author{
Akshada Babar \\ Department of Computer Science \\ Dr.D.Y.Patil Institute of \\ Engineering, Management and \\ Research
}

\author{
Nalini Jagtap \\ Assistant Professor \\ Department of Computer Science \\ Dr.D.Y.Patil Institute of \\ Engineering, Management and
}

Research

\author{
Akshata Mithari \\ Department of Computer Science \\ Dr.D.Y.Patil Institute of \\ Engineering, Management and \\ Research
}

\author{
Aakash Shukla \\ Department of Computer Science \\ Dr.D.Y.Patil Institute of Engineering, Management \\ and Research
}

\author{
Prachi Chaudhari \\ Department of Computer Science \\ Dr.D.Y.Patil Institute of Engineering, Management \\ and Research
}

\begin{abstract}
The problem of fake news is getting serious day by day and it has very detrimental impacts in different spheres like that of politics. Due to the availability of social media, it becomes very easy to spread fake news and it becomes difficult to identify the culprit. As the culprit of such actions is not identified, the problem still persists. Hence, there is a need to identify the source or origin of such fake news to take the necessary action. There are several methods to detect fake news but the common people rarely have time to use these detection techniques and they easily fall prey to such pieces of information. In this paper, we review the different methods that are applied to detect fake news and address it's limitations. We propose the flow of a new blockchain based system that can be used by the news agencies to ensure the validity of the news published. With the help of such a system, the news will be entirely traceable and trackable to every single point in the agency and hence, it becomes easy to find the source and identify the culprit in case of any misinformation.
\end{abstract}

\section{General Terms}

Etereum, Truffle, News Tracing System.

\section{Keywords}

Blockchain, Fake News, Fake News Detection using blockchain, Blockchain to curb fake news.

\section{INTRODUCTION}

The problem of identifying fake news is difficult to tackle because of the dubious nature of the term "fake news". There are different definitions of the term "fake news". Fake news can be determined as the news that aims to deceive people by spreading pieces of information that are not true, partially true or represented in such a way so as to create misinformation. There are different types of fake news as explained in [1]. The intention of spreading these types of information can be unknown, maybe the aim is political and financial gain or the aim is to create a parody for entertainment. There are numerous algorithms available to detect fake news but it is very difficult to identify the source or origin of these news articles. Hence, leaving the culprit free. The availability of social media and free access of the public to social media has led to the increase in this problem. Everyone can access the media and hence, the spread of fake news is fast leading to more victims and also as anyone can post on social media, the amount of fake news is increasing at a faster rate. There are some serious effects of the spread of such news. One such example of this long-lasting problem is the pizzagate conspiracy. In the pizzagate conspiracy[2], the fake news, which claimed that many pizza places in Washington DC are the members of a child sex ring that involved Hilary Clinton [2], was spread. This news was retweeted by many of the opponents of Hilary Clinton and clearly it misguided the public and created a problem for the pizza places [2]. One of the accused pizza places called COMET was a victim of these false allegations, as they had to go through severe threat calls and mails [2]. Also, a man from Washington arrived at the place armed with two guns threatening to kill the owner [2]. Although no one got hurt, this can be an example as to how exaggerated a small mislead news can become and the victims might face severe consequences [1]. Similar to these,there are many other cases where the spread of fake news leads to some severe problems and now the world has recognised the need to have an efficient solution to this problem. The primary aim of this paper is to review the literature regarding the different techniques and models for fake news detection. Furthermore, we identify its limitations and propose a new model for combating the fake news problem by effectively tracking and tracing the news using blockchain technology. We believe that if the origin of this type of fake news is identified then the necessary actions can be taken on the source and gradually the problem will be solved. Our entire proposed system is inspired by the blog written by [3].

\section{LITERATURE SURVEY}

There are a number of techniques that have been used to detect the fake news. Some of the techniques that we studied are as follows:

1] Fake News Detection using a Deep Neural Network [4] : Author:Rohit Kumar Kaliyar

Theory: In this paper the author uses the technologies like machine learning, deep learning and Natural Language 
Processing to develop an application that will determine whether the news is fake news or legitimate. This is the most popular model that we came across during the research. He uses the collection of different datasets from Kaggle, the dataset contains both fake and real news.

The author uses different classification models to test the accuracy of the neural network. He uses the Naive Bayes Model,CNN as a classifier model. Also he uses decision trees,Random forest and K-nearest neighbours for testing the accuracy. The accuracy of the model under different conditions was as follows:

1)When CNN was used the model was accurate up to $98 \%$ [4].

2)When CNN alongwith the combination of LTSM was used, the model accuracy was $97.3 \%$ [4].

3)For the Naive Bayes model, the precision was 90\% [4].

4)When the Decision Tree Regressor was used to classify, the accuracy was reduced to $73 \%$ [4].

5)With Random forest Regressor, the accuracy was 72\% [4].

6)For the k-nearest neighbour method,the precision was $50 \%$ [4].

Hence, the user has explored different Machine Learning models to test the accuracy of the model used to detect fake news [4].

2] Fake News Accuracy using Naive Bayes Classifier [5] :Author: R.J. Poovaraghan, M.V. Keerti Priya, P.V. Sai Surya Vamsi, Mansi Mewara, Sowmya Loganathan

Theory: In this paper the author has described a classification model using the Naive Bayes model to determine the accuracy of the given fake news.

The model works in the following steps:

1)The data is collected from different sources and combined to make a dataset.

2)The dataset is divided into training data and test data.

3)After splitting the data into two, the training data is classified into different groups due to its training.

4)Different vectors are used to keep count of different words and the number of times they appear in the data, the weight is given accordingly and hence, only the most important words are considered.

5)The Naive Bayes algorithm is used to classify the test data into the different groups of the training data to check their accuracy.

6)Hence, whenever the accuracy of the fake news is to be checked, the model can be used to compare it with the previous data and determine its accuracy.

This is the most popular way of detecting the fake news or for classification of news

3] Fake News on Social Media: A Brief Review on Detection Techniques [10] :

Author: Zaitul Iradah Mahid ,Selvakumar Manickam Shankar Karuppayah

Theory: In this paper, the author describes the different methods followed by the different models used to detect fake news.He has classified the models' approaches into different groups mainly :

1)Content based- Here, the model depends on the type of words that are used in the news to determine whether it is fake or legitimate [10].

2) Knowledge-based: Here the model uses a fact checking mechanism to detect whether the news is fake or not. It highly depends on the human experts to determine the authenticity of the news [10].

3) Hybrid-Models: These models use a combination of content-based and knowledge-based approaches to determine the authenticity of the news [10].

Hence, the paper provides an effective review about the different techniques used to detect the fake news.Also,we get a broad classification of the detection techniques.

4]Fake News: A survey of Research,Detection Methods and Opportunities [11] :

Author: Xinyi Zhou, Reza Zafarani

Theory: In this paper the author describes the different types and the effects of fake news. After describing the different types of fake news, he goes on describing the different techniques used to detect fake news. Below is a short summary of the different techniques used for classification :

1)Knowledge based detection [11] : In this category of detection, the main criteria to classify a news as false or true is fact checking. Fact checking is used to determine the authenticity of the news. Fact checking is of two types, expert based fact checking or crowd sourced fact checking. In expert based fact checking, the fact checking machines are operated that go through thousands of facts to generate the results and compare the given piece of information with the already established facts. Whereas in crowd-sourced checking, the users determine whether the article is true or false by rating the phrases used in the article, the article with the best description gets the highest rate.Although, has good accuracy, this type of classification is based on the expert opinions. The working of Knowledge based detection is as follows:

Fact extraction and Fact checking [11]- First the knowledge is extracted from the open web as raw facts and then a knowledge base is formed, further there is a fact checking process where the news article to be classified is compared with the knowledge base to give a result.

2)Style Based Detection [11]: In style based detection model, different deception theories are used to understand how deception techniques work. Basically in this model, different deceptive keywords or phrases are analyzed depending upon highly researched deception techniques and then the probability of the article being deceptive is determined. Unlike the knowledge based technique which was used to find out the authenticity of the fake news, the style based detection technique is used to find the intention of the news, i.e. whether it is deceptive or not.

3)Propagation based deception [11]: According to research conducted by [Vosoughi et al. 2018] , there are some patterns through which we can conclude that the spread of fake news is faster as compared to the propagation of true news. These propagation patterns of the news can be effectively used to develop models that can help detect the authenticity of news. The propagation patterns are classified and identified and then they are linked to the different types of news.

4)Credibility based news detection [11]: According to 
[Silverman 2016], all the fake news in the BuzzFeed resulted from an unreliable source. There is a high chance that the news resulting from an unreliable person or an unreliable source is a fake news. Hence, we can simply identify the fake news depending upon the source of the news. The models deal with finding the source of the news and then classifying it as fake or authentic. Sometimes clickbaits are used to attract user attention but the news might be fake, the news that has a clickbait is generally considered to be unreliable.Hence,the paper provides a brief classification and summary of the wide amount of techniques used for classification.

Table -1: A brief Literature Review.

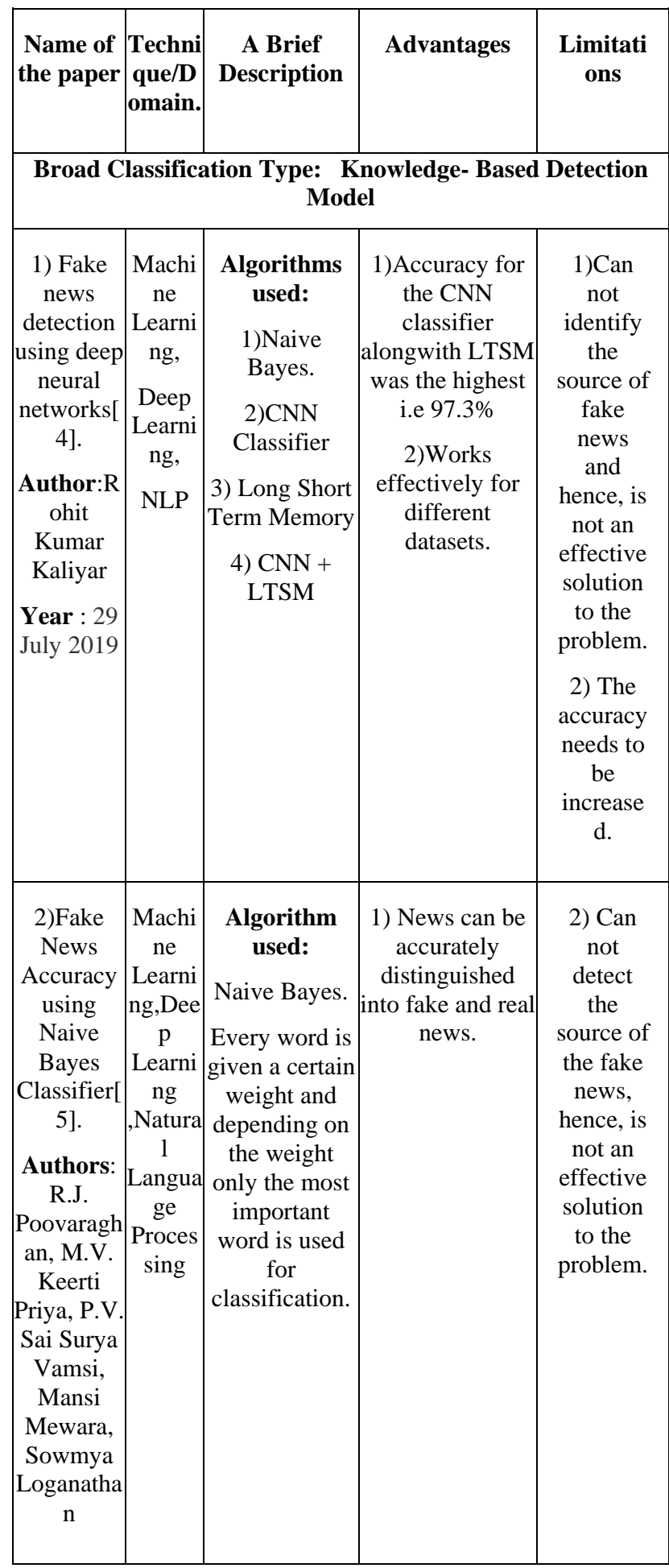

\begin{tabular}{|c|c|c|c|c|}
\hline \multicolumn{5}{|c|}{ Broad Classification Type: Content- Based Detection Model } \\
\hline $\begin{array}{c}\text { 1)Fake } \\
\text { News } \\
\text { Pattern } \\
\text { Recognitio } \\
\text { n using } \\
\text { Linguistic } \\
\text { Analysis[6 } \\
\text { ] } \\
\text { Author: } \\
\text { Amitabha } \\
\text { Dey, } \\
\text { Rafsan } \\
\text { Zani Rafi, } \\
\text { Shahriar } \\
\text { Hasan } \\
\text { Parash, } \\
\text { Sauvik } \\
\text { Kundu } \\
\text { Arko and } \\
\text { Amitabh } \\
\text { Chakrabart } \\
\text { y } \\
\text { Year: } \\
\text { 2018 }\end{array}$ & $\begin{array}{c}\text { Machi } \\
\text { ne } \\
\text { Learni } \\
\text { ng } \\
\\
\\
\end{array}$ & \begin{tabular}{|} 
Algorithms \\
used: \\
1)KNN \\
algorithm \\
Techniques \\
used: \\
Bag of words \\
model
\end{tabular} & $\mid \begin{array}{c}\text { System predicts } \\
\text { the tweet/news to } \\
\text { be fake with an } \\
\text { accuracy of } \\
66.66 \%\end{array}$ & $\begin{array}{l}\text { 1) Every } \\
\text { time we } \\
\text { need to } \\
\text { search } \\
\text { for } \\
\text { similar } \\
\text { news } \\
\text { and } \\
\text { tweets } \\
\text { related } \\
\text { to } \\
\text { articles } \\
\text { to carry } \\
\text { out our } \\
\text { analysis. } \\
\text { 2.) It } \\
\text { performs } \\
\text { detection } \\
\text { based on } \\
\text { content } \\
\text { and not } \\
\text { on the } \\
\text { news } \\
\text { sources }\end{array}$ \\
\hline \begin{tabular}{|} 
2)FAMO \\
US: Fake \\
News \\
Detection \\
Model \\
based on \\
Unified \\
Key \\
Sentence \\
Informatio \\
n [7]. \\
Authors: \\
Namwon \\
Kim, \\
Deokjin \\
Seo Nuua, \\
Chang- \\
Sung \\
Jeong. \\
Year:11 \\
March \\
2019
\end{tabular} & $\begin{array}{c}\text { 1)Natu } \\
\text { ral } \\
\text { langua } \\
\text { ge } \\
\text { process } \\
\text { ing } \\
\text { 2)Deep } \\
\text { learnin } \\
\text { g } \\
\\
\end{array}$ & $\begin{array}{c}\text { Model used: } \\
\text { bilateral multi } \\
\text { perspective } \\
\text { matching(BiM } \\
\text { PM) model } \\
\\
\end{array}$ & \begin{tabular}{|c|} 
1) It perform \\
sentence \\
matching \\
between question \\
and article by \\
using key \\
sentence retrieval \\
based \\
on(BiMPM) \\
model which \\
provides better \\
performance for \\
sentence \\
matching by \\
using two \\
directional \\
bidirectional \\
long short term \\
memory \\
2)It uses NLP \\
techniques based \\
on deep learning \\
for fake news \\
detection to \\
overcome \\
analysis of \\
complicated \\
sentences, and \\
not reflect \\
contextual \\
information.
\end{tabular} & $\begin{array}{l}\text { 1) It } \\
\text { has some } \\
\text { limitatio } \\
\text { ns for } \\
\text { sentence } \\
\text { matchin } \\
\text { g in } \\
\text { Korean } \\
\text { due to } \\
\text { different } \\
\text { morphol } \\
\text { ogical } \\
\text { features } \\
\text { of } \\
\text { Korean } \\
\text { language } \\
\text { 2) It } \\
\text { has some } \\
\text { difficult } \\
\text { y in } \\
\text { finding } \\
\text { the } \\
\text { contextu } \\
\text { al } \\
\text { relation } \\
\text { between } \\
\text { two } \\
\text { sentence } \\
\text { s too } \\
\text { much } \\
\text { apart in } \\
\text { the } \\
\text { article }\end{array}$ \\
\hline
\end{tabular}




\begin{tabular}{|c|c|c|c|c|}
\hline \multicolumn{5}{|c|}{$\begin{array}{c}\text { Broad Classification Type: Credibility Based Detection } \\
\text { Model }\end{array}$} \\
\hline $\begin{array}{l}\text { 1) Using } \\
\text { Blockchai } \\
n \text { to Rein } \\
\text { in the New } \\
\text { Post-Truth } \\
\text { World and } \\
\text { check the } \\
\text { spread of } \\
\text { Fake } \\
\text { News [8]. } \\
\text { Authors: } \\
\text { Adnan } \\
\text { Qayyum, } \\
\text { Junaid } \\
\text { Qadir, } \\
\text { Muhamma } \\
\text { d Umar } \\
\text { Janjua, } \\
\text { and Falak } \\
\text { Sher } \\
\text { Year: } 28 \\
\text { March } \\
\text { 2019 }\end{array}$ & $\begin{array}{l}\text { Blockc } \\
\text { hain } \\
\text { ain } \\
\text { a } \\
\\
\end{array}$ & $\begin{array}{c}\text { The } \\
\text { application } \\
\text { makes use of } \\
\text { Digital } \\
\text { signatures and } \\
\text { hash codes to } \\
\text { ensure the } \\
\text { validity of the } \\
\text { blocks. Blocks } \\
\text { are connected } \\
\text { using } \\
\text { hashpointers. } \\
\text { Hence,it } \\
\text { becomes easy } \\
\text { to back trace } \\
\text { the origin of } \\
\text { the news } \\
\text { publisher.Effe } \\
\text { ctive use of } \\
\text { evolvable } \\
\text { reputation set } \\
\text { is done to } \\
\text { maintain the } \\
\text { status of the } \\
\text { publisher. }\end{array}$ & $\begin{array}{l}\text { 1)This system } \\
\text { will eliminate the } \\
\text { need for a } \\
\text { mediator like } \\
\text { central trust } \\
\text { infrastructure. } \\
\text { 2)The } \\
\text { transparency of } \\
\text { the blockchain } \\
\text { will be helpful in } \\
\text { curbing the fake } \\
\text { news problem } \\
\end{array}$ & $\begin{array}{c}\text { 1)Compl } \\
\text { ex to } \\
\text { impleme } \\
\text { nt. } \\
\text { 2)Blockc } \\
\text { hain } \\
\text { used for } \\
\text { cryptocu } \\
\text { rrencies } \\
\text { cannot } \\
\text { be used } \\
\text { as it is. It } \\
\text { needs to } \\
\text { be } \\
\text { modified } \\
\text { 3)noise } \\
\text { induced } \\
\text { can alter } \\
\text { the } \\
\text { hashcod } \\
\text { e }\end{array}$ \\
\hline $\begin{array}{c}\text { 2)Fake } \\
\text { News: A } \\
\text { Technolog } \\
\text { ical } \\
\text { Approach } \\
\text { to Proving } \\
\text { the } \\
\text { Origins of } \\
\text { Content, } \\
\text { Using } \\
\text { Blockchai } \\
\text { n } \\
\text { Author: } \\
\text { Steven } \\
\text { Huckle, } \\
\text { Martin } \\
\text { White } \\
\text { Year: } \\
\text { December } \\
\text { 2017 }\end{array}$ & $\begin{array}{c}\text { Blockc } \\
\text { hain } \\
\\
\\
\\
\end{array}$ & $\begin{array}{l}\text { Using the } \\
\text { Provenator,Eth } \\
\text { ereum and } \\
\text { React to } \\
\text { construct an } \\
\text { application } \\
\text { that will } \\
\text { ensure the } \\
\text { transparency } \\
\text { of the news } \\
\text { published. }\end{array}$ & $\begin{array}{c}\text { 1)System will be } \\
\text { transparent. } \\
\text { 2)Easy to } \\
\text { validate the } \\
\text { news. } \\
\text { 3)The problem } \\
\text { of fake news can } \\
\text { be easily solved } \\
\text { by the use of this } \\
\text { application. }\end{array}$ & $\begin{array}{l}\text { 1)Diffic } \\
\text { ult to } \\
\text { maintain } \\
\text { decentral } \\
\text { ization. } \\
\text { 2)Chang } \\
\text { ing a } \\
\text { single } \\
\text { pixel } \\
\text { will alter } \\
\text { the } \\
\text { whole } \\
\text { hash } \\
\text { value }\end{array}$ \\
\hline \multicolumn{5}{|c|}{ Base Paper } \\
\hline $\begin{array}{c}\text { Blockchai } \\
\text { n based } \\
\text { Soyabean } \\
\text { Traceabilit } \\
\text { y in } \\
\text { Agricultur } \\
\text { al Supply } \\
\text { Chain [9]. }\end{array}$ & $\begin{array}{c}\text { Blockc } \\
\text { hain }\end{array}$ & $\begin{array}{c}\text { The authors } \\
\text { have proposed } \\
\text { a prototype of } \\
\text { a system } \\
\text { consisting of } \\
\text { seven entities } \\
\text { like } \\
\text { farmers,retaile } \\
\text { rs,customers,et }\end{array}$ & $\begin{array}{l}\text { 1)Ethereum } \\
\text { smart contracts } \\
\text { can be used to } \\
\text { maintain } \\
\text { transparency and } \\
\text { ensure } \\
\text { traceability. } \\
\text { 2)The soybean }\end{array}$ & $\begin{array}{c}\text { 1)Protot } \\
\text { ype does } \\
\text { not } \\
\text { include } \\
\text { proof of } \\
\text { work } \\
\text { and } \\
\text { automate } \\
\text { d }\end{array}$ \\
\hline
\end{tabular}

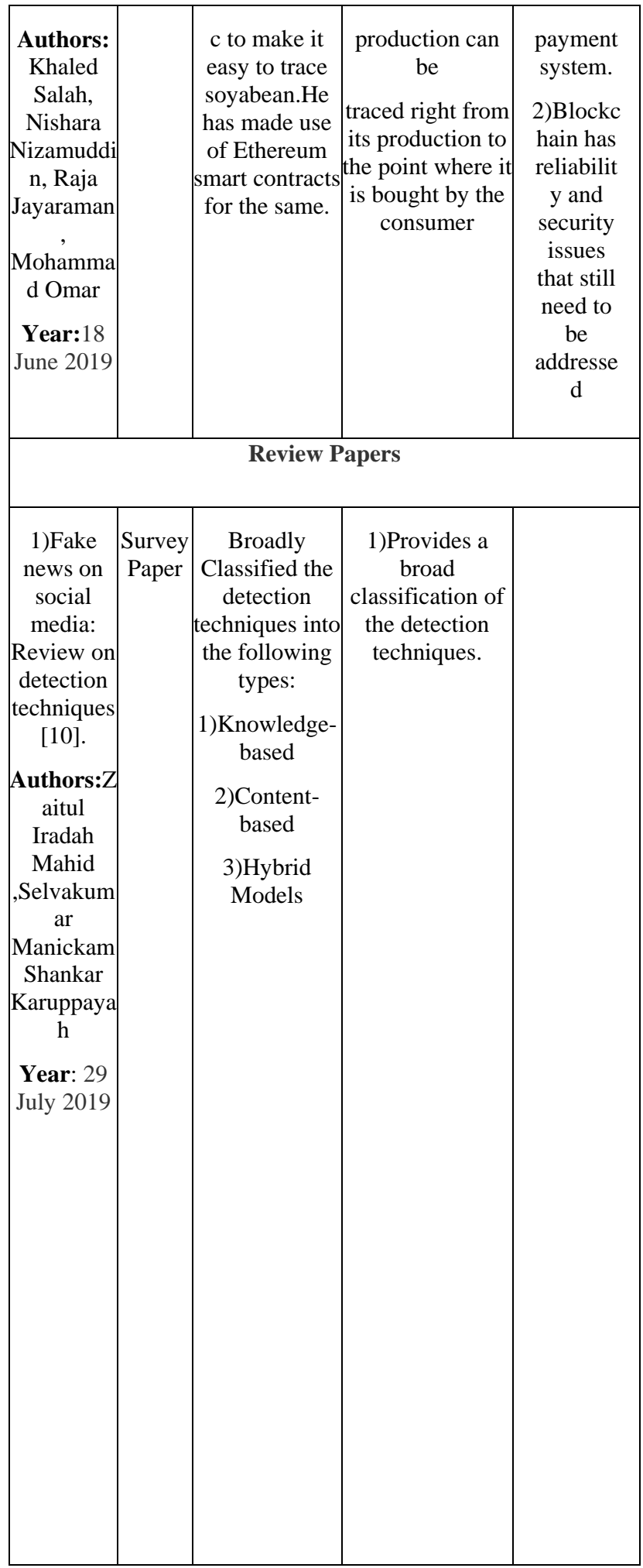




\begin{tabular}{|c|c|c|c|}
\hline \begin{tabular}{|c} 
2)Fake \\
News: A \\
survey of \\
Research,d \\
etection \\
Methods \\
and \\
Opportunit \\
ies [11]. \\
Author: \\
Xinyi \\
Zhou, \\
Reza \\
Zafarani \\
Year: 2 \\
December \\
2018
\end{tabular} & $\begin{array}{c}\text { Survey } \\
\text { Paper } \\
\\
\\
\end{array}$ & $\begin{array}{c}\text { Classification } \\
\text { of the } \\
\text { detection } \\
\text { techniques in } \\
\text { the following } \\
\text { types: } \\
\text { 1)Knowledge } \\
\text { based } \\
\text { 2)Style based } \\
\text { 3)Propagation } \\
\text { based } \\
\text { 4)Credibility }\end{array}$ & $\begin{array}{c}\text { A detailed } \\
\text { classification of } \\
\text { the detection } \\
\text { techniques is } \\
\text { provided. }\end{array}$ \\
\hline \begin{tabular}{|c} 
3) \\
Challenges \\
and \\
opportuniti \\
es in \\
Blockchai \\
n [12]. \\
Author: \\
Zibin \\
Zheng, \\
Hong- \\
Ning Dai, \\
Shaoan \\
Xie, \\
Xiangping \\
Chen \\
Year: \\
October \\
2018
\end{tabular} & \begin{tabular}{|c|} 
Survey \\
Paper
\end{tabular} & $\begin{array}{c}\text { The author } \\
\text { gave the key } \\
\text { characteristic } \\
\text { of Blockchain } \\
\text { 1- } \\
\text { Decentralisatio } \\
n \\
\text { 2-Persistency } \\
\text { 3-Anonymity } \\
\text { 4-Auditability } \\
\text { Blockchain } \\
\text { Categorised } \\
\text { Into three } \\
\text { types } \\
\text { 1)public } \\
\text { blockchain } \\
\text { 2)private } \\
\text { Blockchain } \\
\text { 3) consortium } \\
\text { blockchain } \\
\text { The authors } \\
\text { compares } \\
\text { these from } \\
\text { different } \\
\text { perspectives } \\
\text { As blockchain } \\
\text { is open to } \\
\text { world wide } \\
\text { many users } \\
\text { attracted } \\
\text { therefore } \\
\text { Hyperledger is } \\
\text { developing } \\
\text { the business } \\
\text { and several } \\
\text { companies in } \\
\text { blockchain } \\
\text { frameworks. }\end{array}$ & $\begin{array}{c}\text { 1)Advances on } \\
\text { consensus } \\
\text { algorithms. } \\
\text { 2)Blockchain can } \\
\text { potentially solve } \\
\text { the problems of } \\
\text { Academics and } \\
\text { Web } \\
\text { Community. } \\
\text { Also provides } \\
\text { the application } \\
\text { domain of } \\
\text { blockchain and } \\
\text { its help in current } \\
\text { technology like } \\
\text { IOT. }\end{array}$ \\
\hline
\end{tabular}

\section{LIMITATIONS}

The most popular model to detect the fake news was "The Naive Bayes Classifier [5]", which has been implemented successfully. Although these detection techniques are very accurate, they are not a successful solution to combat fake news. The model can effectively detect whether the news is fake or not but after the news is classified as "Fake", there are no steps taken to identify the source and eliminate it. The fake news can be stopped from propagating further but it can not be eradicated from its root because the Machine Learning Algorithms are incapable of identifying the source of the news. As the source of such news is not eradicated or as there is no action taken on such news providers, the problem of fake news still persists. Before publishing the news, it goes through various editing processes and there is a possibility that one of these editing processes is the source or cause of the fake news. If this source is identified and stopped then there is a possibility that only authentic news providers will exist and the news hence produced will be authentic. The Credibility based news detection model identifies the source as reliable or unreliable, based on these sources the news is further classified, hence, this model can be extended to further eliminate these unreliable sources of news.

\section{PROPOSED MODEL}

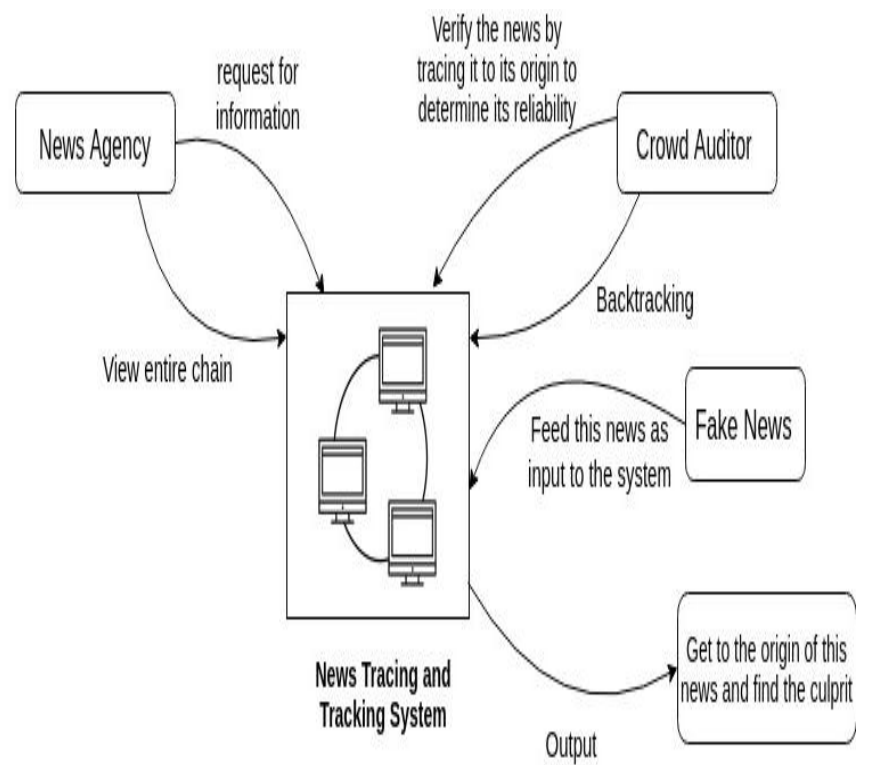

Figure-1: Features of News tracking and Tracing System Using Blockchain

We are proposing a blockchain based news tracking and tracing system through the integration of big data to curb the problem of fake news as inspired from [3]. Our system can be used by news agencies to trace the origin and find the culprit. The system will consist of four main entities :

1)News Agency [3]: Responsible for publishing the news or providing it to the audience.

2)Journalists [3]: Responsible for collecting the news.

3) Editors [3]: Responsible for editing the news to make it presentable.

4) Crowd Auditors [3]: Responsible for validating the news.

Each of these different entities will be connected through a blockchain which will make the news traceable. The system will work as follows: 
1)The journalist will be responsible for creating the first block. The news collected by the journalist will be stored in this block along with the timestamp, hash value and the hashpointer. Timestamp is the time when the block is created. Hash value is the hash value of the block. Hashpointer is used to store the pointer to the next block in the chain.

2)The News Agency will contain the next block. This block will contain the data that is received from the journalist and passed to the editor.

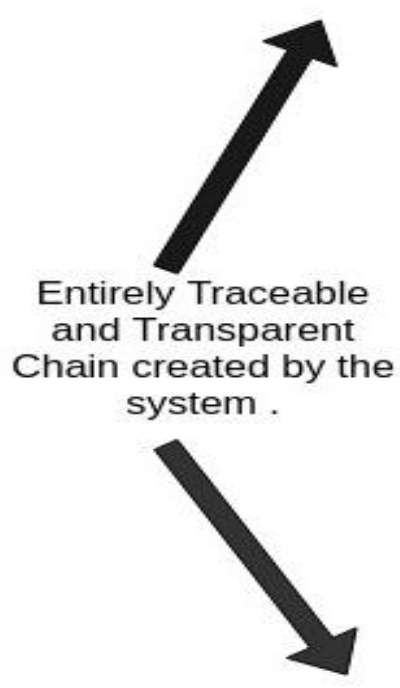

Proposed System Flow

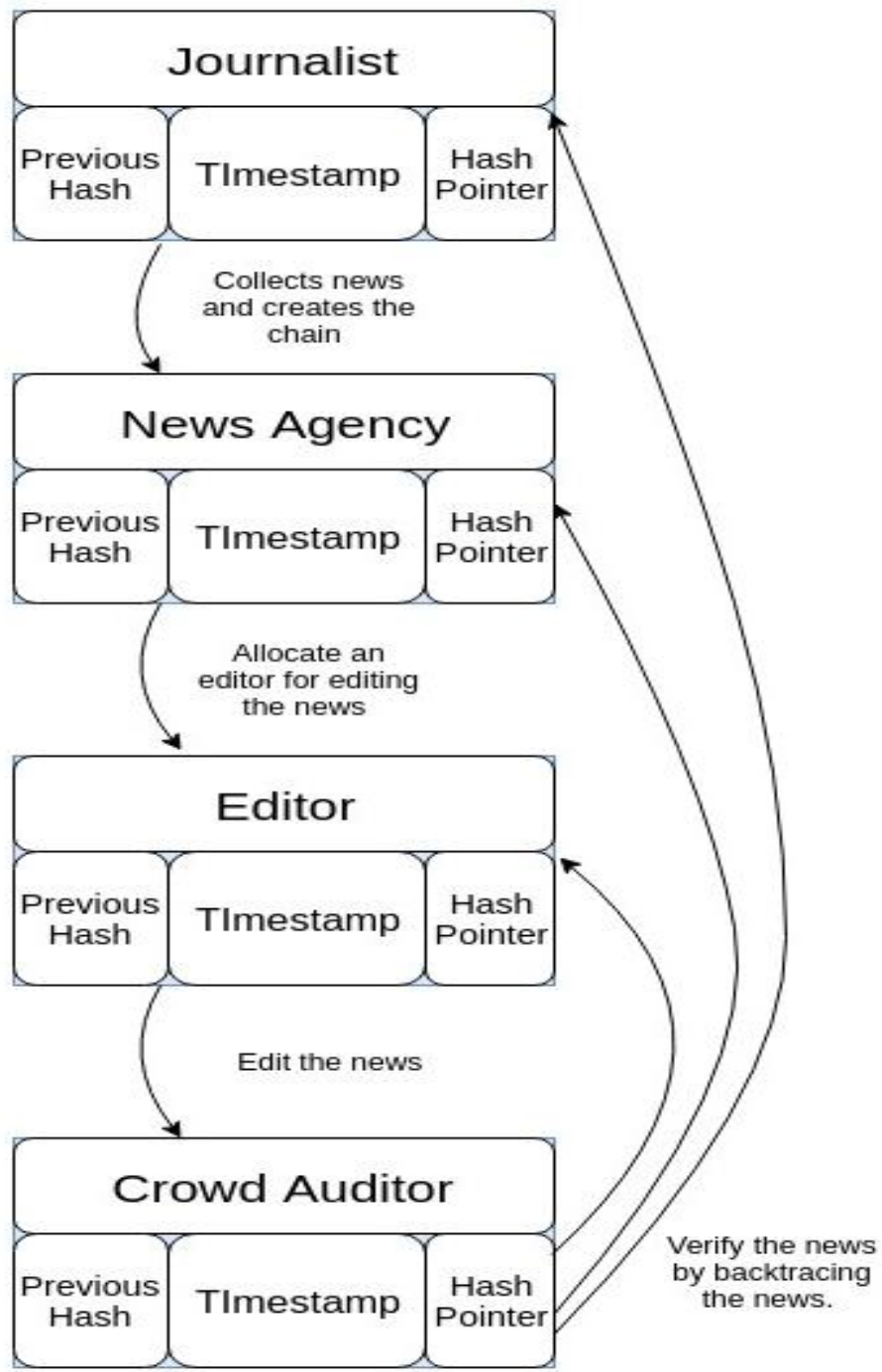

Figure -2: Traceable and Transparent chain formed by the system.

3) The Editor will contain the next block, which will contain the data that was received from the News Agency. The editor can also backtrace to get the information about the journalist who provided this information to the agency

\section{CHALLENGES AND FUTURE SCOPE}

We have several challenges that need to be resolved while building this system. The very first challenge is that of ensuring the hashpointer is calculated correctly. Due to the introduction of noise, the hash values can be altered and it will be difficult to verify the block if the hash value is invalid. The entire system should be built on a decentralized database and this is another challenge that needs to be resolved. The blockchain system used for cryptocurrencies cannot be used as it is, it needs to be changed to suit this project. In the future, this model can be integrated with Big Data to detect fake news and identify its origin. Let us consider a news agency, if the editor modifies the news sent by the journalist, there are two ways how the publishing of this news will be prevented:

1)The block will not be created for this modified news as the hash value will be modified and it will become invalid.

2)If the hash value is valid, then a new block will be added in the chain. Hence, the crowd auditor will be able to trace back to the origin of this news and he can verify if it is fake by considering the reliability of the source. 


\section{CONCLUSIONS}

Overall, the system will help the News Agencies in maintaining a transparent and reliable system to track the news. The origin of the news can be identified easily. News will be validated before publishing. Hence, the problem of fake news will be solved. The system will be strong and hence, difficult to hack. This will keep the news secure and make sure that the information published is original. In the future, this application can be implemented using Hyperledger.

\section{REFERENCES}

[1] G. Kumar. "What is Fake News and its different types". April 3, 2018. [Online]. Available: https://www.jagranjosh.com/general-knowledge/what-isfake-news-and-its-different-types-1522761961-1

[2] Wikipedia."The PizzaGate Conspiracy Theory" Available:https://en.wikipedia.org/wiki/Pizzagate_conspi racy_theory

[3] A. Takyar. "Blockchain in fake news - Transforming News Industry ". [Online] Available: https://www.leewayhertz.com/blockchain-fake-news/

[4] R. Kaliyar. "Fake News Detection using Deep Neural Network (ICCCA 2018)". [Online]. Available: https://ieeexplore.ieee.org/document/8777343

[5] R. Poovaraghan, M. Keerti Priya, P. Sai Surya Vamsi, M. Mewara, S. Loganathan. "Fake News accuracy using Naive Bayes Classifier (May 2019)":[Online]. Available: https://www.ijrte.org/wpcontent/uploads/papers/v8i1C2/ A11660581C219.pdf

[6] A. Dey, R Zani Rafi, S. Hasan Parash, S. Kundu Arko and A. Chakrabarty. "Fake News Pattern Recognition using Linguistic Analysis". 14 February2019.[Online].Available:https://ieeexplore.ieee. org/document/8641018/authors\#authors

[7] N. Kim, D. S. Nuua, Chang-Sung Jeong..."FAMOUS: Fake News Detection Model based on Unified Key Sentence Information".11 March 2019. [Online] Available: https://ieeexplore.ieee.org/document/8663864

[8] Adnan Qayyum, Junaid Qadir, Muhammad Umar Janjua, and Falak Sher. "Using Blockchain to Rein in the New Post-Truth World and check the spread of Fake News". 28 March 2019. [Online] . Available: https://ieeexplore.ieee.org/document/8764081

[9] Khaled Salah, Nishara Nizamuddin, Raja Jayaraman, Mohammad Omar."Blockchain based Soyabean Traceability in Agricultural Supply Chain". 18 June 2019. [Online]. Available: https://ieeexplore.ieee.org/document/8718621

[10] Zaitul Iradah Mahid ,Selvakumar Manickam Shankar Karuppayah"Fake news on social media: Review on detection techniques”. 29 July 2019. [Online].Available: https://ieeexplore.ieee.org/abstract/document/8776689.

[11] Xinyi Zhou, Reza Zafarani."Fake News: A survey of Research,detection Methods and Opportunities". 2 December $2018 . \quad$ [Online]. Available: https://arxiv.org/abs/1812.00315

[12] Zibin Zheng, Hong-Ning Dai, Shaoan Xie, Xiangping Chen."Blockchain :Challenges and opportunities." October 2018. [Online]. Available: https://www.researchgate.net/publication/328338366_B1 ockchain_challenges_and_opportunities_A_survey 